However, M. Prunier makes a number of suggestions for establishing a parallelism between atomic and planetary properties. Some of his arguments from analogy he himself describes as "un peu fragile", or "évidemment assez fragiles", but he considers the real justification of the analogies to lie in the results obtained. One of these concerns the magnetic moment of the earth, which he attributes to its angular momentum. His first attempt gives a numerical value about one-sixth of that observed, but afterwards a reason is found for multiplying this by 5 , bringing it nearly to the value required.

M. Prunier, writing before the appearance of Prof. Blackett's much-discussed article on the magnetic field of massive rotating bodies (Nature, $159,658 ; 1947)$, says (p. 52) : "On est alors conduit à conclure à une relation entre le magnétisme d'une part, et la gravitation et la rotation des planètes d'autre part, de sorte que l'on aurait avec la gravitation des phénomènes magnétiques analogues à ceux que l'on a avec l'électricité, mais seulement beaucoup plus petits. Cela est étonnant dans l'état actuel des théories physiques, et nous ne devons pas y insister."

\section{THE FOREST RESEARCH INSTITUTE OF SWEDEN}

$I^{\mathrm{N}}$ vol. 35 (1946) of Meddelanden Fran Statens Skogs-Forskningsinstitut (published by Central. tryckereit, Esselte, at Stockholm, 1947) there are some interesting papers.

The report opens with a thesis by Erik Bjorkman, well illustrated, on "Storage Decay in Pulpwood Yards and its Prevention". The value of such investigations at the present time needs no stressing. The author's research work has been carried out especially in Norrland, together with certain laboratory experiments concerning the life conditions for different storage-decay fungi. $\mathrm{H}_{\Theta}$ has been able to form certain conclusions on the prevention of damage during storage in pulp-wood yards. During the Second World War, work in the pulp-wood factories was more or less at a standstill, large quantities of wood had to be stored in a limited space for an unforeseen period of several years, and in certain places decay made its appearance. That decay follows unsuitable storing or stacking methods has been long known. Apparently this applies more especially to floated pulp wood. The commonest fungus found in stored pulp wood of Scots pine and Norway spruce is Stereum sanguinolentum which, under unsatisfactory storage conditions, will make its appearance in the summer after the felling of the trees. Others develop. ing early under certain conditions in coniferous wood and also very common are Polyporus abietinus and Corticium evolens. The latter is most common in birch, with other species of Stereum and Polyporus. These are termed the 'early rots'. The 'late rots' appear in long-stored coniferous wood that has not dried satisfactorily. These consist of species of Poria, Trametes, Lenzites, and others. If these fungi are allowed to develop, they will cause more damage than the 'early rots'. The latter mainly consume the lignin before the cellulose, whereas the former chiefly consume the cellulose.

The importance of storage decay in the manufacture of sulphite and sulphate pulps was studied in some hundred test boilings of pine and spruce wood stored for various periods and affected by different of the above-mentioned fungi. The author summarizes the most important results of these test boilings : and then gives a few practical applications of the investigations carried out.

A short paper by M. G. Stalfelt on "The Relation between the Poison Effect of Sodium Chlorate and the Methods of Distribution of the Salt" discusses experiments undertaken with sodium chlorate to poison heather (Calluna vulgaris) and bilberry (Vaccinium myrtillus). A weak solution causes temporary injuries. Only when a sufficient amount of the poison sticks to the basal part of the stem from which buds and shoots are developed will the part of the plant above ground be killed. Fine-grained salt will have greater action than coarse-grained. The best effects are obtained by spraying a concentrated solution with a fine douche. The spraying method requires 10-20 c.c. solution per square metre. Late spring (end of May) and early summer are the best periods to apply the poison.

Erik Bjorkman has a second paper with some interesting photographs of mills and floating logs entitled "On the Development of Log Stain and Storage Decay in Pine Saw-timber during Floating". Sweden is not the only country where such troubles occur, and with other species than the Scots pine. The aim of the author's research in this matter was to fix the time for, and the extent of, the storage injuries in the form of blue stain and storage decay originating in differently treated pine saw-timber during floating in North Sweden. This paper is well worth a study by those commercially interested in these matters.

\section{FORTHCOMING EVENTS}

\author{
Wednesday, May 19
}

Royal METEorological Society (at 49 Cromwell Road, London, S.W.7), at 5 p.m.-Discussion on "Tropical Meteorology".

Royal Microscopical SocieTY (at B.M.A. House, Tavistock Square, London, W.C.1), at 5.30 p.m.-Mr. N. S. MeQueen: "The Work of Percy Smith",

ROYAL STATISTTOAI SOCIETY, NORTH-EASTERN GROUP of the INDUSTRIAI APPIICATTONS SECrion (at the Newcastle Chemical Industries Club, 18 Lovain Place, Newcastle-upon-Tyne), at 6.30 p.m. -Mr. K. A. Brownlee : "Experiments in Industrial Chemistry".

\section{Thursday, May 20}

Institution of Mining AND METALLURgy (at the Geological Society Burlington House, Piccadilly, London, W, 1), at 4 p.m.-Annua General Meeting; at 5.15 p.m.-Mr. S. E. Taylor: Presidential Address.

Chrmucal Societr (joint meeting with the ChEmical and the PHYSICAL SOCIETIES of UNIVRRSITY COLLEGE, in the Physics Department, Universit Pauling, For Mem R.S." "Intermolecular Forces and Biological flcity".

London Mathematical Societr (at Burlington House, Piccadilly, London, W.1), at 5 p.m.- - Symposium on "Some Recent Work in Number-Theory" (introduced by Prof. L. J. Mordell, F.R.S.).

Chrmiral Socinty (joint meeting with the UNIVERSITY College SCIENTIFIC SOCIRTY, at University College, Hull), at 6 p.m.-Mr. R. P. Bell, F.R.S.: "Kinetics of some Organic Halogenation Reactions".

ROYal Statistical SOCIRTY, TEES-SIDE SUb-GROUP of the INDOSTRIAL APPLICATIONS SECTION (at the William Newton School, Norton, Stockton-on-Tees), at 7 p.m.-Mr. K. A. Brownlee : "The Norton, Stockton-on-Tees), at 7 p.m.-Mr. K. A. Brownlee : "The
Use of the Factorial Experiment for Investigating Chemical Processes". Use of the Factorial Experiment for Investigating Chemical Processes
CHEMICAL SOCHET (at Burlington House, Piccadilly, London, CHEMICAL SOCIETY (at Burlington House, Piccadilly, London,
W.1) at 7.30 p.m.-Prof. J. D. Bernal, F.R.S.: Víctor Moritz Gold.1. at 7.30 p.m.

Friday, May 21

Chamcar SocinTy (at King's College, Newcastle-upon-Tyne), at 5 .m.-Prof. A.R. Todd, F.R.S.: "Modern Theories of the Mechanism 5 p.m.-Prof. A. R. Todd, F.R.S.: "Mode.

INSTITUTE of NAVIGATION (at the Royal Geographical Society Kensington Gore, London, S.W.7), at 5.30 p.m.-Mr. Frank Chichester "Meteorology in Aviation-Is it Obsolete?' 